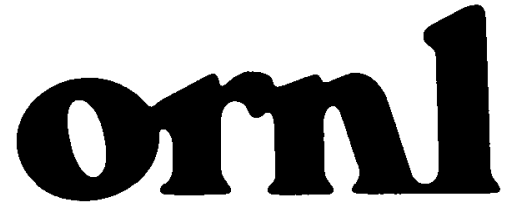

OAK RIDGE

NATIONAL

LABORATORY

MARTIN MARUETIA

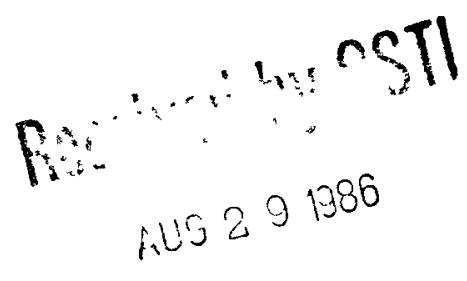

NUREG / CR-4649

ORNL/TM-10099

\title{
Scaling Analysis of the Coupled Heat Transfer Process in the High-Temperature Gas-Cooled Reactor Core
}

J. C. Conklin

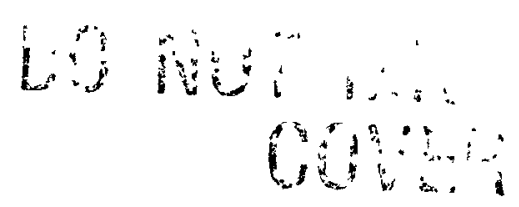

Prepared for the U.S. Nuclear Regulatory Commission

Office of Nuclear Regulatory Research

Under Interagency Agreements DOE 40-551-75 and 40-552-75

\section{OPERATED BY}

MARTIN MARIETTA ENERGY SYSTEMS, INC.

FOR THE UNTED STATES 


\section{DISCLAIMER}

This report was prepared as an account of work sponsored by an agency of the United States Government. Neither the United States Government nor any agency Thereof, nor any of their employees, makes any warranty, express or implied, or assumes any legal liability or responsibility for the accuracy, completeness, or usefulness of any information, apparatus, product, or process disclosed, or represents that its use would not infringe privately owned rights. Reference herein to any specific commercial product, process, or service by trade name, trademark, manufacturer, or otherwise does not necessarily constitute or imply its endorsement, recommendation, or favoring by the United States Government or any agency thereof. The views and opinions of authors expressed herein do not necessarily state or reflect those of the United States Government or any agency thereof. 


\section{DISCLAIMER}

Portions of this document may be illegible in electronic image products. Images are produced from the best available original document. 


\title{
DISCLAIMER
}

This report was prepared as an account of work sponsored by an agency of the United States Government. Neither the United States Government nor any agency thereof, nor any of their employees, makes any warranty, express or implied, or assumes any legal liability or responsibility for the accuracy, completeness, or usefulness of any information, apparatus, product, or process disclosed, or represents that its use would not infringe privately owned rights. Reference herein to any specific commercial product, process, or service by trade name, trademark, manufacturer, or otherwise does not necessarily constitute or imply its endorsement, recommendation, or favoring by the United States Government or any agency thereof. The views and opinions of authors expressed herein do not necessarily state or reflect those of the United States Government or any agency thereof.

Engineering Technology Division

NUREG/CR-4649

ORNL/TM-10099

Dist. Category R8

NUREG/CR- -4649

TI86 015012

\begin{abstract}
SCALING ANALYSIS OF THE COUPLED HEAT TRANSFER PROCESS
IN THE HIGH-TEMPERATURE GAS-COOLED REACTOR CORE
\end{abstract}

J. C. Conk1in

Manuscript Completed - July 25, 1986

Date Published - August 1986

NOTICE: This document contains information of a preliminary nature. It is subject to revision or correction and therefore does not represent a final report.

\author{
Prepared for the \\ U.S. Nuclear Regulatory Commission \\ Office of Nuclear Regulatory Research \\ Under Interagency Agreement DOE 40-551-75 and 40-552-75
}

NRC FIN No. BO122

Prepared by the

OAK RIDGE NATIONAL LABORATORY

Oak Ridge, Tennessee 37831

operated by

MARTIN MARIETTA ENERGY SYSTEMS, INC.

for the

U.S. DEPARTMENT OF ENERGY

under Contract No. DE-AC05-84OR21400 


\section{CONTENTS}

Page

NOMENCLATURE $\quad \ldots \ldots \ldots \ldots \ldots \ldots \ldots \ldots \ldots \ldots \ldots \ldots \ldots \ldots \ldots \ldots \ldots \ldots \ldots \ldots \ldots \ldots \ldots$ v

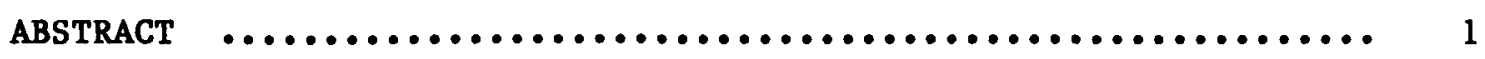

1. INTRODUCTION $\ldots \ldots \ldots \ldots \ldots \ldots \ldots \ldots \ldots \ldots \ldots \ldots \ldots \ldots \ldots \ldots \ldots \ldots \ldots . \ldots 1$

2. DEVELOPMENT OF DIMENSIONLESS GROUPS $\ldots \ldots \ldots \ldots \ldots \ldots \ldots \ldots \ldots \ldots \ldots$

3. FULL-POWER, FULL-FLOW ANALYSIS $\ldots \ldots \ldots \ldots \ldots \ldots \ldots \ldots \ldots \ldots \ldots$

3.1. Fluid Analysis $\ldots \ldots \ldots \ldots \ldots \ldots \ldots \ldots \ldots \ldots \ldots \ldots \ldots \ldots \ldots$

3.2. Thermally Expandable Flow Analysis ................ 14

3.3 Solid Component Analysis ....................... 17

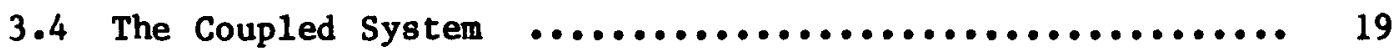

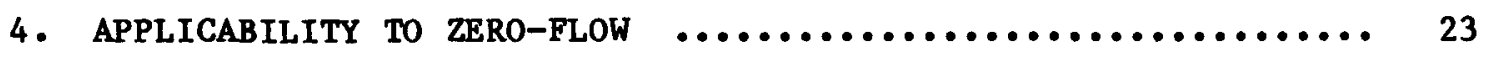

5. CONCLUSIONS $\ldots \ldots \ldots \ldots \ldots \ldots \ldots \ldots \ldots \ldots \ldots \ldots \ldots \ldots \ldots \ldots \ldots \ldots \ldots \ldots . \ldots \ldots$

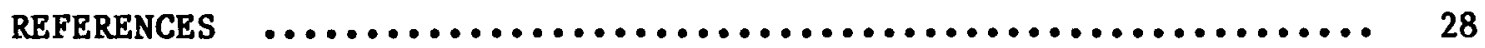




\section{NOTICE}

This report was prepared as an account of work sponsored by an agency of the United States Government. Neither the United States Government nor any agency thereof, or any of their employees, makes any warranty, expressed or implied, or assumes any legal liability or responsibility for any third party's use, or the results of such use, of any information, apparatus product or process disclosed in this report, or represents that its use by such third party would not infringe privately owned rights.

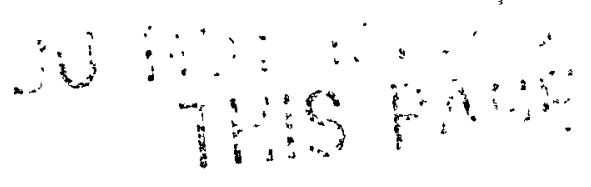

Available from

Superintendent of Documents

U.S. Government Printing Office

Post Office Box 37082

Washington, D.C. 20013-7982

and

National Technical Information Service

Springfield, VA 22161 


\section{NOMENCLATURE}

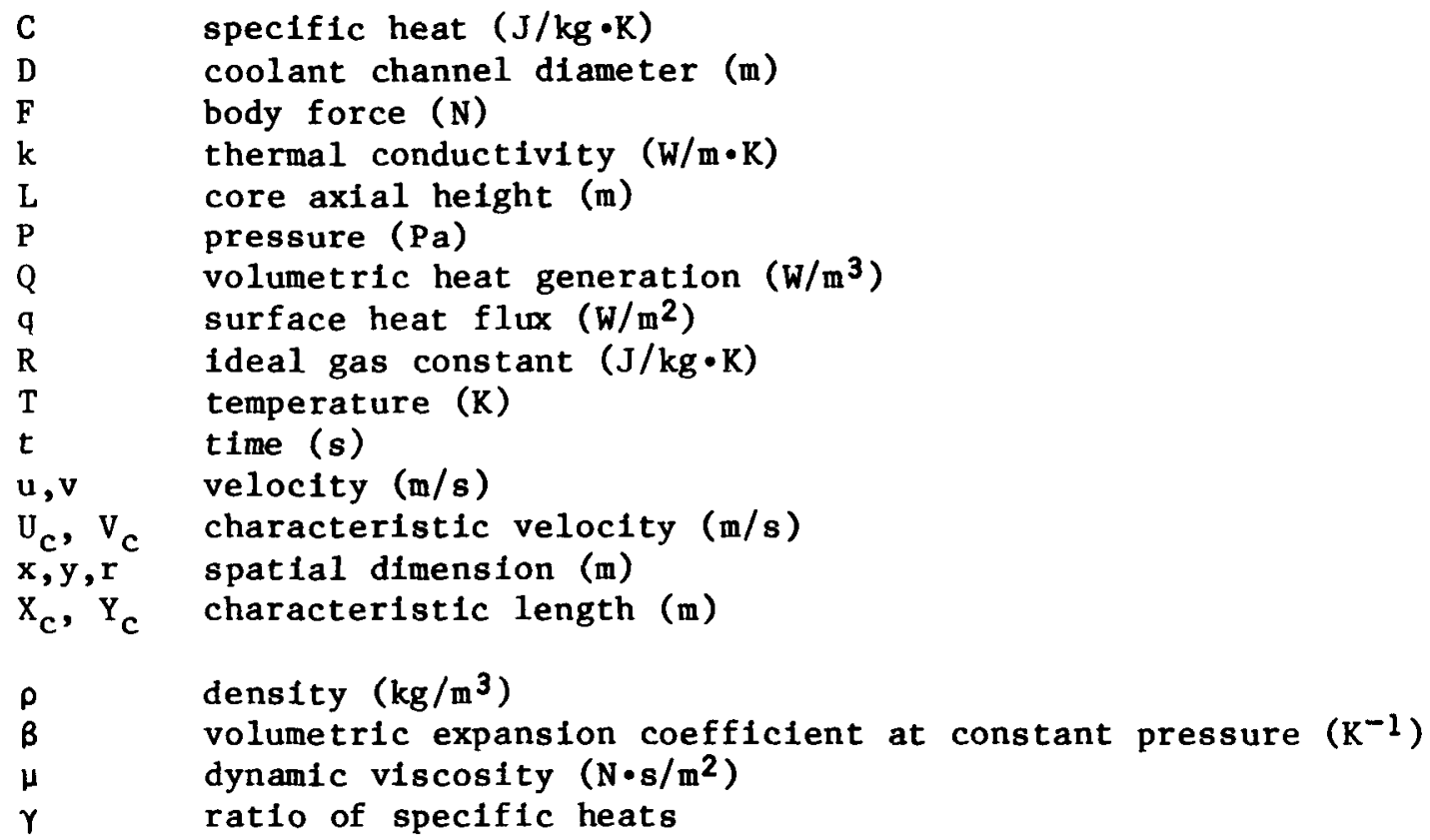


SCALING ANALYSIS OF THE COUPLED HEAT TRANSFER PROCESS IN THE HIGH-TEMPERATURE GAS-COOLED REACTOR CORE

\author{
J. C. Conklin
}

\begin{abstract}
The differential equations representing the coupled heat transfer from the solid nuclear core components to the hellum in the coolant channels are scaled in terms of representative quantities. This scaling process identifies the relative importance of the various terms of the coupled differential equations. The relative importance of these terms is then used to simplify the numerical solution of the coupled heat transfer for two bounding cases of full-power operation and depressurization from full-system operating pressure for the Fort St. Vrain High-Temperature Gas-Cooled Reactor. This analysis rigorously justifies the simplified system of equations used in the nuclear safety analysis effort at Oak Ridge National Laboratory.
\end{abstract}

\title{
1. INTRODUCTION
}

The complete system of nonlinear Navier-Stokes differential equations together with the additional conservation of energy differential equations for the combined heat transfer from a nuclear reactor core to its primary coolant, represent an extensive and expensive problem. Identifying relatively small terms in the differential equations will justify neglecting these terms, simplifying the numerical solution of these coupled equations without significantly affecting the accuracy.

The differential equations that describe the transient and spatial response of the parameters of interest for the different solution domains of solid and fluid will have intrinsic reference quantities that will describe the magnitude of the response. These equations, including the interface conditions between the different solution domains, will be scaled so that the relative magnitude of each equation term will indicate the relative importance for the particular effect represented by that term. This information will be used to justify simplification of the governing equations for appropriate ranges of the independent variables.

The intent of this analysis is to analyze the components of governing equations for their relative magnitude to simplify numerical computation. The actual value as determined by computation for the parameter of interest should be little affected by deletion of the components that were shown to have orders of magnitude smaller influence. 
An important term that will be used extensively is "unit order." This term is loosely defined to mean an absolute magnitude somewhere between one-half and five.

The governing equations are written so that each term in the differential equation is represented by a dimensionless term having unit order preceded by a coefficient that represents its relative magnitude. Each independent and dependent varlable will be replaced by a product of the form $\stackrel{*}{T}=T_{c} T$, where in this case $\stackrel{*}{T}$ is the dependent variable of temperature, $T_{c}$ is a characteristic value of temperature valid for the range of interest, and $T$ is the dimensionless temperature of unit order. The remalning variables are listed in the nomenclature. The star superscript will represent a dimensional quantity, and the $c$ subscript will represent a characteristic quantity.

These characteristic values will be manipulated so that a nondimensional grouping of characteristic terms will appear before a nondimensional term of unit order. This unit-order term will indicate the physical phenomenon. Its coefficient, consisting of the characteristic quantities, will indicate the relative importance of that phenomenon in the solution. This procedure, developed by Segell for perturbation methods of solution, will be applied to the coupled or conjugate heat transfer problem for the Fort St. Vrain (FSV) High-Temperature GasCooled Reactor (HTGR). The characteristic values will be selected to represent a range of expected behavior and not just simply to have the correct units. To solve the system of equations, certain auxiliary relationships are necessary and will be used to help identify appropriate choices for the characteristic values.

For the analysis of the transient response of the FSV-HTGR, the solution domain for the problem will be a typical fuel block. The fuel block will be split into two differential equation solution domains representing the solid and the gas. These two domains will be connected by the interface conditions of wall temperature and heat flux. These two solution domains form a conjugate heat transfer problem, where the effects of one domain upon the other must be considered. 


\section{DEVELOPMENT OF DIMENSIONLESS GROUPS}

The differential equations to be solved for the convecting fluid are those of continuity, conservation of momentum, and conservation of energy for a compressible, Newtonian fluid as developed by $\mathrm{Pai}^{2}$ and Batchelor. 3 These are written in repeated index tensor notation as follows :

$$
\begin{aligned}
& \frac{\partial \rho}{\partial t}+\frac{\partial}{\partial x_{j}^{*}}\left(\stackrel{* \star}{\rho u_{j}}\right)=0 \text {, }
\end{aligned}
$$

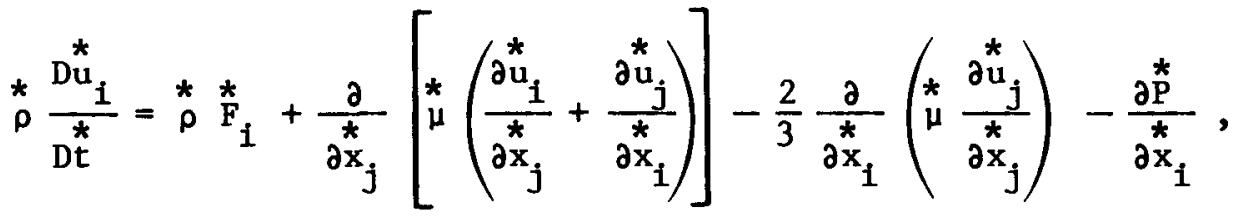

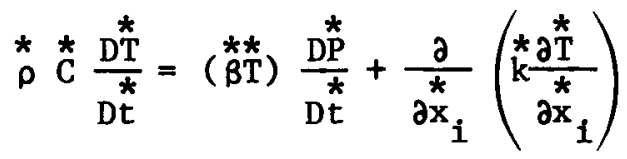

$$
\begin{aligned}
& +\stackrel{*}{Q}+\stackrel{*}{\mu} \frac{\partial u_{1}^{*}}{\partial x_{j}^{*}}\left[\left(\frac{\partial u_{i}}{\partial x_{j}}+\frac{\partial u_{j}^{*}}{\partial x_{i}}\right)-\frac{2}{3} \frac{\partial u_{k}^{*}}{\partial x_{k}^{*}} \oint_{j}\right] \text {, }
\end{aligned}
$$

where $\delta_{i j}=1$ if $i=j$ and $\delta_{i j}=0$ if $i \neq j$. The term $\frac{D}{D t}$ represents the material derivative.

The differential equation governing the temperature of the solid components is obtained by setting the convective and pressure terms of the above conservation of energy equation [Eq. (3)] to zero.

Beginning with the continuity equation [Eq. (1)], the dimensional terms are replaced with the product of the characteristic and unit-order terms to result in the following form.

$$
\frac{1}{t_{c}} \frac{\partial_{\rho}}{\partial t}+\frac{u_{c j}}{x_{c j}} \frac{\partial\left(p u_{j}\right)}{\partial x_{j}}=0 .
$$

For the rest of this analysis, the repeated index notation will be dropped, and the typical two-dimensional (2-D) Cartesian notation will be used, where $u$ represents a dimensionless streamwlse velocity in the $x$ 
direction and $v$ represents a velocity in the normal direction $y$. The continuity equation transforms to

$$
\frac{1}{t_{c}} \frac{\partial \rho}{\partial t}+\frac{U_{c}}{X_{c}} \frac{\partial(\rho u)}{\partial x}+\frac{V_{c}}{Y_{c}} \frac{\partial(\rho v)}{\partial y}=0 .
$$

Multiplying by $\mathrm{X}_{\mathrm{c}} / \mathrm{U}_{\mathrm{c}}$ results in

$$
\left(\frac{X_{c}}{t_{c} U_{c}}\right)\left[\frac{\partial \rho}{\partial t}\right]+\frac{\partial(\rho u)}{\partial x}+\left(\frac{v_{c} X_{c}}{U_{c} Y_{c}}\right)\left[\frac{\partial(\rho v)}{\partial y}\right]=0 .
$$

For the proper choice of the characteristic variables, the differential terms should be of unit order in this equation, with the dimensionless groupings for the first and third terms representing the relative magnitude with respect to the second. Physically the groupings $\frac{X_{c}}{t_{c} U_{c}}$ and $\frac{V_{c} X_{c}}{U_{c} Y_{c}}$ represent the relative importance of the density time variation and $y$ convective terms with respect to the $x$ convective term in the continuity equation. The characteristic value for the coefficient terms will remain unspecified for now. For the remainder of this analysis, a term having square brackets enclosing dimensionless quantities will be of unit order. The leading coefficient of this term will generally have parentheses, and its order of magnitude will indicate the relative importance of the following unit-order term.

The conservation of momentum equation [Eq. (2)] reduced to 2-D Cartesian coordinates for the $x$ direction is

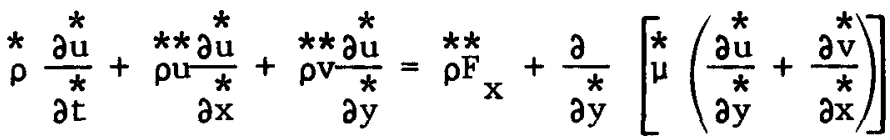

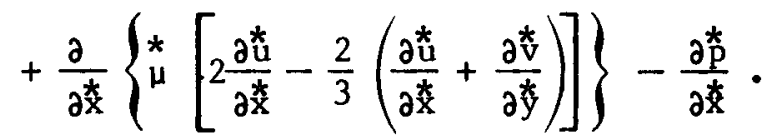

Substitution of the characteristic values and division by the spatial convective terms in the $x$ direction yields 


$$
\begin{aligned}
&\left(\frac{X_{c}}{t_{c} U_{c}}\right)\left[\rho \frac{\partial u}{\partial t}\right]+[\rho u\left.\frac{\partial u}{\partial x}\right]+\left(\frac{X_{c} V_{c}}{Y_{c} U_{c}}\right)\left[\rho v \frac{\partial u}{\partial y}\right]=\left(\frac{X_{c} F_{c x}}{U_{c}{ }^{2}}\right)\left[\rho F_{x}\right]-\left(\frac{P_{c}}{\rho U_{c}^{2}}\right)\left[\frac{\partial P}{\partial x}\right] \\
&+\left(\frac{\mu_{c}}{\rho_{c} U_{c} X_{c}}\right)\left(\frac{X_{c}}{Y_{c}}\right)^{2}\left[\frac{\partial}{\partial y}\left\{\mu\left(\frac{\partial u}{\partial y}+\frac{Y_{c} V_{c}}{X_{c} U_{c}} \frac{\partial v}{\partial x}\right)\right\}\right. \\
&\left.+\left(\frac{Y_{c}}{X_{c}}\right)^{2} \frac{\partial}{\partial x}\left\{2 \mu \frac{\partial u}{\partial x}-\frac{2}{3} \mu\left(\frac{\partial u}{\partial x}+\left(\frac{X_{c} V_{c}}{Y_{c} U_{c}}\right) \frac{\partial v}{\partial y}\right)\right\}\right] .
\end{aligned}
$$

The conservation of energy equation reduced to 2-D Cartesian coordinates with constant thermophysical properties of viscosity and thermal conductivity reduces to

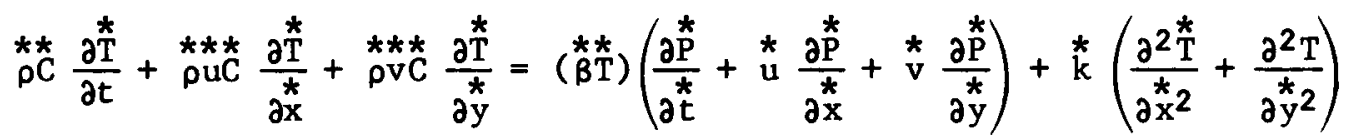

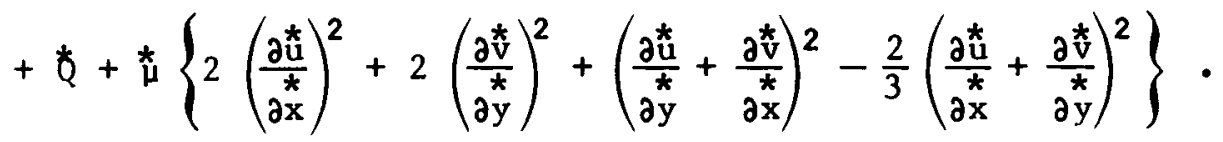

Note that density and pressure variations are retained. Substituting the characteristic quantities and rearranging so that the nondimensionalized convective term for the $x$ direction (the second term on the left-hand side) has a unit coefficient yields

$$
\begin{aligned}
&\left(\frac{X_{c}}{t_{c} U_{c}}\right)\left[\rho c \frac{\partial T}{\partial t}\right]\left.+\rho C u \frac{\partial T}{\partial x}\right]+\left(\frac{X_{c} V_{c}}{Y_{c} U_{c}}\right)\left[\rho C v \frac{\partial T}{\partial x}\right]=\left(\frac{(\stackrel{* *}{\beta T}) P_{c}}{\rho_{c} C_{c} T_{c}}\right)\left[\left(\frac{X_{c}}{t_{c} U_{c}}\right) \frac{\partial P}{\partial t}+u \frac{\partial P}{\partial x}\right. \\
&\left.+\left(\frac{V_{c} X_{c}}{U_{c} Y_{c}}\right) v \frac{\partial P}{\partial y}\right]+\left(\frac{k_{c}}{\rho_{c} U_{c} C_{c} X_{c}}\right)\left(\frac{Y_{c}}{X_{c}}\right)^{2}\left[k\left\{\left(\frac{Y_{c}}{X_{c}}\right)^{2} \frac{\partial^{2} T}{\partial x^{2}}+\frac{\partial^{2} T}{\partial y^{2}}\right\}\right] \\
&+\left(\frac{Q_{c} X_{c}}{\rho_{c} U_{c} C_{c} T_{c}}\right)[Q]+\left(\frac{\mu_{c} U_{c}}{\rho_{c} C_{c} X_{c} T_{c}}\right)\left(\frac{X_{c}}{Y_{c}}\right)^{2}\left[\left(\frac{Y_{c}}{X_{c}}\right)^{2} \mu\left[\frac{\partial u}{\partial x}\right]^{2}+2 \mu\left(\frac{X_{c} V_{c}}{Y_{c} U_{c}}\right)^{2}\left[\frac{\partial v}{\partial y}\right]^{2}\right. \\
&\left.+\mu\left[\frac{\partial u}{\partial y}+\frac{V_{c} Y_{c}}{U_{c} X_{c}} \frac{\partial v}{\partial x}\right]^{2}-\frac{2}{3}\left(\frac{Y_{c}}{X_{c}}\right)^{2} \mu\left[\frac{\partial u}{\partial x}+\frac{X_{c} V_{c}}{Y_{c} U_{c}} \frac{\partial v}{\partial y}\right]^{2}\right]
\end{aligned}
$$


Note that many of the characteristic groupings are repeated in all three equations. Cholces must be made for the characteristic values appropriate for the geometry, flow, and other circumstances of the analysis. The effect of these choices in all three equations must be evaluated. Rescaling of the characteristic groupings might be appropriate for the different FSV transients.

The characteristic time $t_{c}$ is still undetermined for the coupled problem of the FSV core. There will be two characteristic times representative of the temporal behavior in each solution domain. Because this is a conjugate problem, the behavior of the solid fuel and moderator components will be coupled to the fluid behavior. Although the spatial solution domains for the solid and gas are separate, they are connected by the common axial helght of the core, where the coolant channel surface temperature and heat flux are boundary conditions for both solution domains.

The conservation of energy equation for the solid components can be written by setting the convective, pressure work, and viscous work terms of the general constant property energy conservation equation [Eq. (9)] to zero. In dimensional notation, this equation is

$$
\stackrel{*}{\rho} \stackrel{*}{\mathrm{C}} \underset{\frac{\partial}{\mathrm{T}}}{\partial{ }_{\mathrm{t}}^{*}}=\stackrel{*}{\mathrm{k}}\left(\frac{\partial^{2} \stackrel{*}{\mathrm{~T}}}{\partial \mathrm{x}^{2}}+\frac{\partial^{2} \stackrel{*}{\mathrm{~T}}}{\partial \mathrm{y}^{2}}\right)+\stackrel{*}{\mathrm{Q}}
$$

Substitution of the characteristic and dimensionless unit-order terms yields

$$
\left(\frac{\rho_{c} C_{c} T_{c}}{Q_{c} t_{c}}\right)\left[\rho c \frac{\partial T}{\partial t}\right]=\frac{k_{c} T_{c}}{Q_{c} Y_{c}^{2}}\left[k\left(\frac{Y_{c}}{X_{c}}\right)^{2} \frac{\partial^{2} T}{\partial x^{2}}+k \frac{\partial^{2} T}{\partial y^{2}}\right]+[Q] .
$$

This completes the general scaling analysis. Chapters 3 and 4 detail the simplification of the governing equations for subsonic flow and, after selection of the characteristic quantities, further simplification of the equations specifically for FSV conditions. 


\section{FULL-POWER, FULL-FLOW ANALYSIS}

This section reports the analysis of the entire coupled set of differential equations for FSV. The behavior of the fluld conservation equations at full power operating conditions is analyzed in Sect. 3.1. The fluid conservation equations are further analyzed with the assumption of relatively low flow velocity with respect to sonic in the Sect. 3.2. The behavior of the conservation of energy equation for the solid core components is addressed in the sect. 3.3. Finally in Sect. 3.4, the set of differential equations are coupled together for the conjugate heat transfer problem with evaluation of the behavior of the resultant system of equations.

\subsection{Fluid Analysis}

The fluid will be assumed to vary in the $x$ direction only (1.e., $V_{c}$ is zero). No heat sources are in the fluid. The fluid conservation equations immediately reduce to the following:

$$
\begin{aligned}
& \left(\frac{X_{c}}{t_{c} U_{c}}\right)\left(\frac{\partial \rho}{\partial t}\right)+\left[\frac{\partial(\rho u)}{\partial x}\right]=0, \\
& \left(\frac{X_{c}}{t_{c} U_{c}}\right)\left[\rho \frac{\partial u}{\partial t}\right]+\left[\rho u \frac{\partial u}{\partial x}\right]=\left(\frac{X_{c} F_{c x}}{U_{c}^{2}}\right)\left[\rho F_{x}\right]-\left(\frac{P_{c}}{\rho_{c} U_{c}^{2}}\right)\left[\frac{\partial P}{\partial x}\right] \\
& +\left(\frac{\mu_{c}}{\rho_{c} U_{c} X_{c}}\right)\left(\frac{X_{c}}{Y_{c}}\right)^{2}\left[\mu \frac{\partial^{2} u}{\partial y^{2}}+\left(\frac{Y_{c}}{X_{c}}\right)^{2} \frac{4}{3} \mu \frac{\partial^{2} u}{\partial x^{2}}\right] \text {, } \\
& \left(\frac{X_{c}}{t_{c} U_{c}}\right)\left[\rho C \frac{\partial T}{\partial t}\right]+\left[\rho C u \frac{\partial T}{\partial x}\right]=\left(\frac{(\stackrel{\star \star *}{B T}) P_{c}}{\rho_{c} C_{c} T_{c}}\right)\left[\left(\frac{X_{c}}{t_{c} U_{c}}\right) \frac{\partial P}{\partial t}+u \frac{\partial P}{\partial x}\right] \\
& +\left(\frac{k_{c}}{\rho_{c}{ }_{c}{ }^{C}{ }_{c} X_{c}}\right)\left(\frac{X_{c}}{Y_{c}}\right)^{2}\left[\left(\frac{Y_{c}}{X_{c}}\right)^{2} k \frac{\partial^{2} T}{\partial x^{2}}+k \frac{\partial^{2} T}{\partial y^{2}}\right] \\
& +\left(\frac{\mu_{c}{ }_{c}}{\rho_{c} C_{c} X_{c} T_{c}}\right)\left(\frac{X_{c}}{Y_{c}}\right)^{2}\left[\mu\left(\frac{Y_{c}}{X_{c}}\right)^{2} \frac{4}{3}\left(\frac{\partial u}{\partial x}\right)^{2}+\mu\left(\frac{\partial u}{\partial y}\right)^{2}\right] .
\end{aligned}
$$


The characteristic values for velocity $U_{c}$ and $x$ direction $X_{c}$ are now determined. The velocity of the gas is known as a function of the helium circulator speed and inlet conditions. For full-power conditions at FSV, this value is $27.3 \mathrm{~m} / \mathrm{s}$ in the core coolant channels. The axial length of the core coolant channel would be an appropriate characteristic dimension for the $x$ direction, which for FSV is $6.3 \mathrm{~m}$. The core transit time of $0.235 \mathrm{~s}$ is then a characteristic time scale $t_{c}$.

Upon inspection of the continuity equation, the fluid transit time $X_{c} / U_{c}$ would be an appropriate characteristic time, if time-dependent density effects are to be of the same order of magnitude as the spatial effects on the continuity relationship. If time-dependent density effects are not of the same order of magnitude as the spatial, this chotce of characteristic time would not be appropriate and would be revealed in subsequent portions of the analysis. The analysis must be started somewhere, and this characteristic quantity is choser for the time-dependent circumstance.

An appropriate characteristic pressure for this forced convection process that exists for full-power operation of FSV would be the dynamic pressure $\rho_{c} U_{c}^{2}$. For the computational modeling of FSV at or near expected operating conditions, local pressure and buoyant effects on the velocity profile are expected to be negligible. These assumptions must be checked if conditions very much different from the normal and of $f-$ normal operating conditions expected at FSV are present. The characteristic pressure might be different than the dynamic pressure if the channel pressure drop is on the order of the absolute pressure or if the hot (cold) channel wall temperature induces a buoyant force on the coolant flow that significantly affects the flow velocity profile in the channel. This latter condition only applies to buoyant conditions in the channel that influence the streamwise velocity. Buoyancy forces between channels caused by differential heating would, as compared with local buoyancy effects inside a channel, create a thermosyphon to circulate helium up the hot channels and down the cold channels. This induces a streamwise velocity, which would then be an appropriate characteristic convection velocity.

The streamwise body force $F_{c x}$ is the force induced by gravity on the helium coolant in the channel. This body force per unit mass would simply be the acceleration of gravity, which is in the negative $x$ direction or $-\mathrm{g}$. Substitution of the characteristic body force and characteristic pressure into the governing equations yields the following:

$$
\left(\frac{X_{c}}{t_{c} U_{c}}\right)\left[\frac{\partial \rho}{\partial t}\right]+\left[\frac{\partial(p u)}{\partial x}\right]=0,
$$




$$
\begin{aligned}
& \left(\frac{x_{c}}{t_{c} U_{c}}\right)\left[\rho \frac{\partial u}{\partial t}\right]+\left[\rho u \frac{\partial u}{\partial x}\right]=-\left(\frac{x_{c}^{g}}{U_{c}^{2}}\right)\left[\rho F_{x}\right]-\left[\frac{\partial P}{\partial x}\right] \\
& +\left(\frac{\mu_{c}}{\rho_{c} U_{c} X_{c}}\right)\left(\frac{X_{c}}{Y_{c}}\right)^{2}\left[\mu \frac{\partial^{2} u}{\partial y^{2}}+\left(\frac{Y_{c}}{X_{c}}\right)^{2} \frac{4}{3} \mu \frac{\partial^{2} u}{\partial x^{2}}\right] \text {, } \\
& \left(\frac{x_{c}}{t_{c} U_{c}}\right)\left[\rho C \frac{\partial T}{\partial t}\right]+\left[\rho C u \frac{\partial T}{\partial x}\right]=(\stackrel{\star *}{\beta T})\left(\frac{U_{c}^{2}}{C_{c} T_{c}}\right)\left[\left(\frac{X_{c}}{t_{c} U_{c}}\right) \frac{\partial P}{\partial t}+u \frac{\partial P}{\partial x}\right] \\
& +\left(\frac{k_{c}}{\rho_{c}{ }_{c}^{C} C_{c}}\right)\left(\frac{X_{c}}{Y_{c}}\right)^{2}\left[k\left(\frac{Y_{c}}{X_{c}}\right)^{2} \frac{\partial^{2} T}{\partial x^{2}}+k \frac{\partial^{2} T}{\partial y^{2}}\right] \\
& +\left(\frac{\mu_{c} U_{c}}{\rho_{c} C_{c} X_{c} T_{c}}\right)\left(\frac{X_{c}}{Y_{c}}\right)^{2}\left[\mu\left(\frac{Y_{c}}{X_{c}}\right)^{2} \frac{4}{3}\left(\frac{\partial u}{\partial x}\right)^{2}+\mu\left(\frac{\partial u}{\partial y}\right)^{2}\right] \text {. }
\end{aligned}
$$

Certain dimensionless groups can be immediately recognized for the coefficients. These numbers, as described by White $e^{4}$ are the Froude number $\left(\mathrm{Fr}=\mathrm{U}_{\mathrm{c}}{ }^{2} / \mathrm{gX}_{\mathrm{c}}\right)$, Reynolds number $\left(\operatorname{Re}=\rho_{c} \mathrm{U}_{c} \mathrm{X}_{c} / \mu_{c}\right)$, Eckert number (Ec $\left.=U_{c}{ }^{2} / C_{c} T_{c}\right)$, and Peclet number $\left(P e=\rho_{c} U_{c} C_{c} X_{c} / k_{c}\right)$. The Peclet number is the product of the Reynolds number and the Prandt 1 number $\operatorname{Pr}=\frac{\mu_{c} c_{c}}{k_{c}}$.

The characteristic dimensions of the Reynolds and Peclet numbers for closed channel flow are usually expressed in hydraulic diameter, which, for the case of tube flow, reduces to the tube diameter. The Reynolds number, as previously defined, has the characteristic dimension expressed as a flow length; this is typical for an open flow, such as flow past a flat plate. These two dimensionless numbers in this analysis could be based on the channel diameter, requiring introduction of the length-to-diameter ratio in the coefficient of the unit-order viscous drag term in Eq. (17) and the coefficient of the unit-order heat conduction term in Eq. (18). Doing this would not affect the value of the entire leading coefficient of the unit-order terms. The numerical values of the entire leading coefficients of all the terms are of interest in this scaling analysis, leaving the choice of the channel length or diameter of determining the Reynolds and Peclet numbers arbitrary. yields

Introducing these dimensionless groups into the governing equations 


$$
\begin{aligned}
& \left(\frac{X_{c}}{t_{c} U_{c}}\right)\left[\frac{\partial \rho}{\partial t}\right]+\left[\frac{\partial(\rho u)}{\partial x}\right]=0 \text {, } \\
& \left(\frac{X_{c}}{t_{c} U_{c}}\right)\left[\rho \frac{\partial u}{\partial t}\right]+\left[\rho u \frac{\partial u}{\partial x}\right]=-\frac{1}{F r}\left[\rho F_{x}\right]-\left[\frac{\partial P}{\partial x}\right] \\
& +\frac{1}{\operatorname{Re}}\left(\frac{X_{c}}{Y_{c}}\right)^{2}\left[\mu \frac{\partial^{2} u}{\partial y^{2}}+\left(\frac{Y_{c}}{X_{c}}\right)^{2} \frac{4}{3} \mu \frac{\partial^{2} u}{\partial x^{2}}\right] \\
& \left(\frac{X c}{t_{c} U_{c}}\right)\left[\rho C \frac{\partial T}{\partial t}\right]+\left[\rho C u \frac{\partial T}{\partial x}\right]=(\stackrel{* *}{\beta T}) E c\left[\left(\frac{X_{c}}{T_{c} U_{c}}\right) \frac{\partial P}{\partial t}+u \frac{\partial P}{\partial x}\right] \\
& +\frac{1}{\operatorname{Re} \operatorname{Pr}}\left(\frac{X_{c}}{Y_{c}}\right)^{2}\left[k\left(\frac{Y_{c}}{X_{c}}\right)^{2} \frac{\partial^{2} T}{\partial x^{2}}+k \frac{\partial^{2} T}{\partial y^{2}}\right] \\
& +\frac{E c}{\operatorname{Re}}\left(\frac{X_{c}}{Y_{c}}\right)^{2}\left[\mu\left(\frac{Y_{c}}{X_{c}}\right)^{2} \frac{4}{3}\left(\frac{\partial u}{\partial x}\right)^{2}+\mu\left(\frac{\partial u}{\partial y}\right)^{2}\right]
\end{aligned}
$$

Note that the aspect ratio $\mathrm{X}_{\mathrm{c}} / \mathrm{Y}_{\mathrm{c}}$ remains unspecified, with all dimensionless numbers defined with the characteristic length $X_{c} \cdot$ This length is chosen because the primary interest for this situation is convection in the streamwise direction $x$. The square of the aspect ratio appears in the coefficient of the terms representing unit viscous and conduction effects to balance the equations at steady state conditions. Certain physical properties must be determined first.

The FSV core inlet temperature of $685 \mathrm{~K}$ is used as a reference only for the determination of the characteristic viscosity and thermal conductivity. The characteristic value of density is obtained by using the ideal gas law with this inlet temperature and an inlet pressure of 4.75 $\mathrm{MPa}$. The characteristic temperature $\mathrm{T}_{c}$ will be different from this inlet temperature and will be subsequently defined. Use of the core inlet conditions for evaluation of the characteristic physical properties yields the following values from Goodman et al.: 5 


$$
\begin{aligned}
& \mathrm{C}_{c}=5193 \mathrm{~J} / \mathrm{kg} \cdot \mathrm{K}, \\
& k_{c}=0.27 \mathrm{~W} / \mathrm{mK}, \\
& \mu_{c}=3.5 \times 10^{-5} \mathrm{~N} \cdot \mathrm{s} / \mathrm{m}^{2}, \\
& \rho_{c}=3.3 \mathrm{~kg} / \mathrm{m}^{3},
\end{aligned}
$$

The product $(\stackrel{* *}{\beta T})$ for an ideal gas is untty. For helium at the FSV operating conditions, this value will be acceptable.

The appropriate value for the characteristic temperature $T_{c}$ is now determined. From inspection of the original dimensional equations, the only term where the absolute temperature itself appears is in the coefficient of the pressure-work term in the energy equation. This term has already been considered. The other terms where the temperature appears are in the form of a differential because of the original derivation by $\mathrm{Pai}, 2$ where the energy change or difference for the unit volume is derived. Because a reference temperature could be included within the differential expression for temperature change without affecting the energy balance represented by the conservation of energy equation ( $\mathrm{Pai}$ appropriately used an ideal reference temperature of absolute zero), the characteristic temperature $T_{c}$ should represent a temperature difference. An appropriate value for $T_{c}$ would then be the coolant temperature rise along the channel length. For FSV at full power, this value is $376 \mathrm{~K}$.

Substitution of these physical property values, along with the previously determined values of length and veloctty, yleld the following dimensionless numbers:

$$
\begin{aligned}
& \operatorname{Re}=1.7 \times 10^{7}, \\
& \mathrm{Pe}=1.2 \times 10^{7}, \\
& \mathrm{Fr}=12.0, \\
& \mathrm{Ec}=3.8 \times 10^{-4} .
\end{aligned}
$$

The characteristic aspect ratio remains to be determined. This aspect ratio need be not geometric in nature.

For steady state conditions, $t_{c}=\infty$, and in the absence of heat sources in the helium channel, the energy equation reduces to 


$$
\begin{aligned}
{\left[\rho \operatorname{Cu} \frac{\partial T}{\partial x}\right]=E c\left[u \frac{\partial P}{\partial x}\right]+\frac{1}{\operatorname{Pe}}\left(\frac{X_{c}}{Y_{c}}\right)^{2}\left[k\left(\frac{Y_{c}}{X_{c}}\right)^{2} \frac{\partial^{2} T}{\partial x^{2}}+k \frac{\partial^{2} T}{\partial y^{2}}\right] } \\
+\frac{E c}{\operatorname{Re}}\left(\frac{X_{c}}{Y_{c}}\right)^{2}\left[\mu\left(\frac{Y_{c}}{X_{c}}\right)^{2} \frac{4}{3}\left(\frac{\partial u}{\partial x}\right)^{2}+\mu\left(\frac{\partial u}{\partial y}\right)^{2}\right] .
\end{aligned}
$$

Because each of the square bracketed terms is of unit-order, at least one of the coefficients on the right-hand side must also be of untt order to balance the convective term on the left. Because the Eckert, Peclet, and Reynolds numbers have already been determined, the aspect ratio then will be uniquely determined. From setting the coefficient of the conduction term to unity, $Y_{c}=X_{c} \mathrm{Pe}^{-1 / 2}$. Substitution of numerical values yields $Y_{c}=1.8 \times 10^{-3} \mathrm{~m}$. Note that this value is less than the coolant channel diameter of $15.5 \times 10^{-3} \mathrm{~m}$ and it can be considered as a distance from the channel wall into the coolant over which thermal conduction is the heat transfer mechanism.

Substitution of these numerical values into the transient heat conservation equation yields

$$
\begin{array}{r}
\left(\frac{X_{c}}{t_{c} U_{c}}\right)\left[\rho C \frac{\partial T}{\partial t}\right]+ \\
\left.+\rho c u \frac{\partial T}{\partial x}\right]=\left(3.8 \times 10^{-4}\right)\left[\left(\frac{X_{c}}{t_{c} U_{c}}\right) \frac{\partial P}{\partial t}+u \frac{\partial P}{\partial x}\right] \\
+k\left(8.3 \times 10^{-8} \frac{\partial^{2} T}{\partial x^{2}}+\frac{\partial^{2} T}{\partial y^{2}}\right) \\
+\left(2.5 \times 10^{-4}\right) \mu\left[1.1 \times 10^{-7}\left(\frac{\partial u}{\partial x}\right)^{2}+\left(\frac{\partial u}{\partial y}\right)^{2}\right] .
\end{array}
$$

An inspection of this equation and its coefficients shows that the effects of pressure work, viscous dissipation, and axial thermal conduction are at least two orders of magnitude less than thermal convection and transverse thermal conduction. The energy conservation equation reduces to

$$
\left(\frac{x_{c}}{t_{c} U_{c}}\right)\left[\rho C \frac{\partial T}{\partial t}\right]+\left[\rho C u \frac{\partial T}{\partial x}\right]=\left[k \frac{\partial^{2} T}{\partial y^{2}}\right] \text {. }
$$


The transient contribution and the characteristic time will be left undetermined until the heat transfer from the solid fuel block is considered.

Upon substitution of the previously determined values of Froude number, Reynolds number, and aspect ratio, the momentum conservation equation can be written

$$
\begin{aligned}
\left(\frac{X_{c}}{t_{c} U_{c}}\right)\left[\rho \frac{\partial u}{\partial t}\right]+\left[\rho u \frac{\partial u}{\partial x}\right]=-1 & \times 10^{-1}\left[\rho F_{X}\right]-\left[\frac{\partial P}{\partial x}\right] \\
& +3\left[\mu\left(\frac{\partial^{2} u}{\partial y^{2}}+1.1 \times 10^{-7} \frac{\partial^{2} u}{\partial x^{2}}\right)\right] .
\end{aligned}
$$

Inspection of this equation at steady state operating conditions indicates that to within an order of magnitude, the channel pressure drop consists of convective acceleration (second term on the left-hand side) and viscous effects (third term on the right-hand side). The body force term at these full-power operating conditions is negligible. However, during of f-normal events, such as loss of forced circulation, the body force term may not be neglected and indeed induces a characteristic channel velocity.

The conservation of momentum relationship, Eq. (20), contains a convective acceleration term, which accounts for the fluid kinetic energy change as the fluid flows through the channel. This term will be rewritten so that the density change of the fluid caused by heating (cooling) as the fluid flows through the channel is specifically included in the the momentum conservation equation.

The mass conservation term can be expanded to

$$
\left(\frac{x_{c}}{t_{c} U_{c}}\right)\left[\frac{\partial \rho}{\partial t}\right]+\left[\rho \frac{\partial u}{\partial x}\right]+\left[u \frac{\partial \rho}{\partial x}\right]=0 .
$$
Solving for $\rho \frac{\partial u}{\partial x}$ and substituting into the convective acceleration term
yields

$$
\begin{aligned}
\left(\frac{X_{c}}{t_{c} U_{c}}\right)\left[\rho \frac{\partial u}{\partial t}-u \frac{\partial \rho}{\partial t}\right] & -\left[u^{2} \frac{\partial \rho}{\partial x}\right]= \\
& -\frac{1}{F r}\left[\rho F_{x}\right]-\left[\frac{\partial P}{\partial x}\right]+\frac{1}{R e}\left(\frac{X_{C}}{Y_{c}}\right)^{2}\left[\mu \frac{\partial^{2} u}{\partial y^{2}}\right] .
\end{aligned}
$$


Note that only a constant viscosity assumption has been made. Density and pressure variations remain in the equation.

\subsection{Therma11y Expandable Flow Analys is}

The scaled conservation of momentum [Eq. (27)] and conservation of energy [Eq. (24)], with the insignificant pressure work and viscous dissipation neglected, form a coupled set of differential equations for the fluid. Solution of these two equations can be difficult for high fluid velocities. This section will justify simplification of the fluid equations for relatively low fluid velocities as compared with sonic but still allow for thermal expansion effects caused by heating or cooling the fluid.

Because helium is a simple compressible substance, two intensive state variables are necessary and sufficient to describe the thermodynamic state of the gas. The total differential of density can then be written as

$$
\mathrm{d}_{\rho}^{*}=\left.\frac{\partial \stackrel{*}{\rho}}{\partial \stackrel{*}{\mathrm{P}}}\right|_{\mathrm{T}} ^{*} \mathrm{d \stackrel {* } { \mathrm { P } }}+\left.\frac{\partial \stackrel{*}{\rho}}{\partial \stackrel{*}{\mathrm{~T}}}\right|_{\stackrel{*}{\mathrm{P}}} \stackrel{\mathrm{d}}{\mathrm{T}}
$$

At expected operating conditions, the perfect gas relationship will represent helium behavior very well. Taking partial derivatives and substituting into the total differential yields

$$
\mathrm{d}_{\rho}^{*}=\frac{1}{\mathrm{RT}^{*}} \mathrm{~d}^{*} \mathrm{P}-\frac{\stackrel{*}{\mathrm{P}}}{\mathrm{RT}^{*}{ }^{*}} \mathrm{~d}^{*} \mathrm{~T},
$$

or

$$
\frac{\mathrm{d}_{\rho}^{*}}{\stackrel{*}{\rho}}=\frac{\mathrm{d}_{\mathrm{P}}^{*}}{\stackrel{*}{\mathrm{P}}}-\frac{\mathrm{d}^{*} \mathrm{~T}}{\mathrm{~T}}
$$

Insertion of the scaling representations yields

$$
\left(\frac{\rho_{c_{1}}}{\rho_{c_{2}}}\right)\left[\frac{d \rho}{\rho}\right]=\left(\frac{P_{c_{1}}}{P_{c_{2}}}\right)\left[\frac{d P}{P}\right]-\left(\frac{T_{c_{1}}}{T_{c_{2}}}\right)\left[\frac{d T}{T}\right] .
$$


The subscripts 1 and 2 are included to denote the possibilities for different characteristic values. As before, the square-bracketed terms are of unit order. In this case they represent differential changes of unit order for density, pressure, and temperature. Because density is the dependent variable whose unit response is of interest, the density ratio $\rho_{c_{1}} / \rho_{c_{2}}$ is set to unity to study the effect on density of the independent variables. This requires that one or both of the coefficient terms for the bracketed independent variable terms must also be of unit order for consistency.

$P_{c}$ represents the characteristic value for pressure change, and $P_{c_{2}}$ represents the characteristic value for absolute pressure, with analogous descriptions for $T_{c_{1}}$ and $T_{c_{2}} \cdot P_{c_{2}}$ and $T_{c_{2}}$ must be set to the core inlet values for pressure and temperature of $4.75 \mathrm{MPa}$ and $685 \mathrm{~K}$. These conditions will now be referred to as $P_{i n}$ and $T_{1 n^{*}}$. The characteristic value for pressure change $P_{c}$ for a forced convection flow is the dynamic pressure $\rho U^{2}$, which is $2.5 \mathrm{kPa}$ for FSV at full-power operating conditions. The characteristic value for temperature change for forced convection flow is the core temperature rise of $376 \mathrm{~K}$. Substitution into the scaled total density derivative yields

$$
\left[\frac{\mathrm{d} \rho}{\rho}\right]=5 \times 10^{-4}\left[\frac{\mathrm{dP}}{\mathrm{P}}\right]-0.5\left[\frac{\mathrm{dT}}{\mathrm{T}}\right] \text {. }
$$

For the specified FSV operating conditions, this scaling analysis shows that the density change caused by pressure change is negligible when compared with the density change caused by temperature. Hall et al.6 refer to this as the "thermally expandable assumption."

However, this total differential expression for density change will be retained to show its effect on the momentum conservation equation. Multiplying through by $\rho$ yields

$$
\mathrm{d} \rho=\left(\frac{\rho_{c} \mathrm{U}_{c}{ }^{2}}{\mathrm{P}_{\text {in }}}\right)\left[\frac{\rho}{\mathrm{P}} \mathrm{dP}\right]+\left(\frac{\mathrm{T}_{\mathrm{c}}}{\mathrm{T}_{\text {in }}}\right)\left[\frac{\rho \mathrm{dT}}{\mathrm{T}}\right] .
$$

Because $P_{\text {in }}$ is set to the channel inlet pressure and the ideal gas law is applicable

$$
\mathrm{d} \rho=\left(\frac{\mathrm{U}^{2}}{\mathrm{RT}_{i n}}\right)\left[\frac{\rho}{\mathrm{P}} \mathrm{dP}\right]+\left(\frac{\mathrm{T}_{c}}{\mathrm{~T}_{i n}}\right)\left[\frac{\rho \mathrm{dT}}{\mathrm{T}}\right] .
$$


$\left(\mathrm{RT}_{\mathrm{fn}_{\mathrm{n}}}\right.$ ) can be recognized as the square of the local sonic velocity divided by the ratio of specific heats $\gamma$. The coefficient of the dimensionless unit-order pressure change can be rewritten in terms of the Mach number Ma. The differential density change is now written

$$
d_{\rho}=\gamma \mathrm{Ma}^{2}\left[\frac{\rho}{\mathrm{P}} \mathrm{dP}\right]+\left(\frac{\mathrm{T}_{c}}{\mathrm{~T}_{\text {in }}}\right)\left[\frac{\rho \mathrm{dT}}{\mathrm{T}}\right] .
$$

This total differential with respect to the thermodynamic state variables can be transformed Into a partial differential with respect to space and time and substituted into the scaled momentum conservation equation, Eq. (27). Upon rearrangement, the momentum equation is

$$
\begin{gathered}
\left(\frac{X_{c}}{t_{c}{ }_{c}}\right)\left[\rho \frac{\partial u}{\partial t}-\gamma M a^{2}\left[\frac{\rho u}{P} \frac{\partial P}{\partial t}\right]+\left(\frac{T_{c}}{T_{1 n}}\right)\left[\frac{\rho u}{T} \frac{\partial T}{\partial t}\right]\right]+\left(\frac{T_{c}}{T_{1 n}}\right)\left[\frac{\rho u^{2}}{T} \frac{\partial T}{\partial x}\right] \\
=-\frac{1}{F r}\left[\rho F_{X}\right]-\left(1-\gamma M^{2}\left[\frac{\rho u^{2}}{P}\right]\right)\left[\frac{\partial P}{\partial x}\right]+\frac{1}{\operatorname{Re}}\left(\frac{X_{c}}{Y_{c}}\right)^{2}\left[\mu \frac{\partial^{2} u}{\partial y^{2}}\right] .
\end{gathered}
$$

This is a "fully compressible" relationship that couples the energy conservation equation to the momentum equation through the equation of state. It is a formidable task to solve it either analytically or computationally.

For flow situations where the Mach number is sufficiently low $(<0.3)$, this equation can be simplified to the following:

$$
\begin{aligned}
\left(\frac{X_{c}}{t_{c}{ }_{c}}\right) & {\left[\rho \frac{\partial u}{\partial t}+\left(\frac{T_{c}}{T_{i n}}\right)\left[\frac{\rho u}{T} \frac{\partial T}{\partial t}\right]\right]+\left(\frac{T_{c}}{T_{i n}}\right)\left[\frac{\rho u^{2}}{T} \frac{\partial T}{\partial x}\right] } \\
& =-\frac{1}{F r}\left[\rho F_{x}\right]-\left[\frac{\partial P}{\partial x}\right]+\frac{1}{\operatorname{Re}}\left(\frac{X_{c}}{Y_{c}}\right)^{2}\left[\mu \frac{\partial^{2} u}{\partial y^{2}}\right] .
\end{aligned}
$$

Note that this form of the momentum equation was developed using the small Mach number approximation, but it is still coupled to the energy conservation equation through the spatial acceleration term. This term simply accounts for kinetic energy changes caused by heating (cooling) the helium. Although the momentum conservation equation is coupled to the fluid energy conservation equation, no acoustic pressure 
waves can be supported at low Mach numbers because of the absence of a time-dependent pressure term. Equation (37) does not represent a fully compressible flow situation; however, density changes caused by adding or subtracting thermal energy to or from the fluid are represented.

\subsection{Solid Component Analysis}

All characteristic quantities must be representative of the core materials. The physical properties of density, specific heat, and thermal conductivity will be taken from the values presented in the FSV Final Safety Analysis Report (FSAR). 7 These values are

$$
\begin{aligned}
& \rho_{c}=1700 \mathrm{~kg} / \mathrm{m}^{3}, \\
& c_{c}=1380 \mathrm{~J} / \mathrm{kg} \cdot \mathrm{K}, \\
& \mathrm{k}_{\mathrm{c}}=17.3 \mathrm{~W} / \mathrm{mK} .
\end{aligned}
$$

The conservation of energy equation (Eq. 12) for the solid components was written in Sect. 2. Equation (12) is repeated.

$$
\left(\frac{\rho_{c} C_{c} T_{c}}{Q_{c}{ }^{T}}\right)\left[\rho_{c} \frac{\partial T}{\partial t}\right]=\left(\frac{k_{c}{ }_{c}}{Q_{c} Y_{c}^{2}}\right)\left[k\left(\frac{Y_{c}}{X_{c}}\right)^{2} \frac{\partial^{2} T}{\partial x^{2}}+k \frac{\partial^{2} T}{\partial y^{2}}\right]+[Q] .
$$

Two characteristic quantities are now determined. An appropriate value of characteristic volumetric heat strength would be the power density, which for FSV is $6.3 \mathrm{MW} / \mathrm{m}^{3}$. The characteristic quantity of $\mathrm{X}_{c}$ must be the core height, or helium flow length, of $6.3 \mathrm{~m}$ to be consistent with the fluid solution domain. This leaves three characteristic quantities to be determined.

At steady state $\left(t_{c}=\infty\right)$ the heat generated in the core is completely removed by the convecting coolant. This heat must be conducted through the solid core components. The coefficient of the square bracketed term representing solid thermal conduction must be of unit order, because the heat generated in the core must be of the same magnitude as the conducted heat at steady state. Therefore,

$$
\frac{{ }_{{ }_{c}} T_{c}}{Q_{c} Y_{c}^{2}}=1
$$

Additionally, the heat conducted through the graphite must be convected into the helium coolant. The coolant channel surface heat flux at any axial location is governed by the Fourier heat conduction law of 


$$
\stackrel{*}{q}=-\stackrel{*}{k} \frac{\partial^{*}}{\partial{ }^{*}}
$$

Replacing the dimensional terms by the characteristic quantity and dimensionless unit-order terms yields

$$
[q]=-\left(\frac{k_{c} T_{c}}{q_{c} Y_{c}}\right)\left[k \frac{\partial T}{\partial y}\right] \text {, }
$$

where the coefficient term must be of unit order for the unit-order heat flux to balance the unit-order temperature gradient.

Substituting this relationship for characteristic coolant channel surface heat flux into the relationship that balances the steady state heat conduction and generation [Eq. (38)] yields the y characteristic dimension

$$
\mathrm{Y}_{\mathrm{c}}=\frac{\mathrm{q}_{\mathrm{c}}}{\mathrm{Q}_{\mathrm{c}}} \text {. }
$$

The surface heat flux $q_{c}$ is simply the total heat convected into the helfum divided by the coolant channel surface area. For the FSV core at full-power conditions,

$$
q_{c}=\frac{\rho_{c} U_{c} C_{c} T^{D}}{4 X_{c}}
$$

where $D$ is the coolant channel diameter, and the other characteristic quantities are representative of the helium coolant. Substitution of numerical values yields a characteristic surface heat flux of $108 \mathrm{~kW} / \mathrm{m}^{2}$. The characteristic core heat conduction heat length $\mathrm{Y}_{c}$ is then $17.0 \mathrm{~mm}$. Axial heat conduction is therefore negligible under the condition that all generated heat is removed by convection. As the coefficient of the square bracketed term representing core thermal conduction must be of unit order, the characteristic temperature difference of the core materials is then determined to be $106 \mathrm{~K}$.

A characteristic time for the transient temperature response of the core temperature can now be determined by setting the coefficient of the unit-order energy storage term to unity or 


$$
\frac{\rho_{c} c_{c}^{T} c}{Q_{c}{ }^{t}}=1 .
$$

Substitution of the previously determined characteristic values for the core yields a characteristic time of $40 \mathrm{~s}$. Note that this quantity is on the order of 200 times that of the gas characteristic response time of $0.235 \mathrm{~s}$ derived in Sect. 3.1 .

\subsection{The Coupled System}

Al1 the differential equations must be considered simultaneously, because this is a conjugate problem where the interface conditions of heat flux and temperature are contained within the problem definition. A final dimensioning parameter $\varepsilon$ is defined as the ratio of these two characteristic times for the fluid and the solid components or

$$
\varepsilon=\frac{t_{c}(\text { fluid })}{t_{c}(\text { solid })}
$$

Introducing this parameter into the scaled equations of both solution domains by using the solid component characteristic time as the time period of interest for solution of the coupled problem yields the following set of equations.

$$
\begin{aligned}
& {\left[\rho \quad C \quad \frac{\partial T}{\partial t}\right]=\left[k \frac{\partial^{2} T}{\partial y^{2}}\right]+[Q] \quad(\text { solid), }} \\
& \varepsilon\left[\frac{\partial \rho}{\partial t}\right]=-\left[\frac{\partial}{\partial x}(\rho u)\right] \quad(f 1 u i d) \text {, } \\
& \varepsilon\left[\rho \quad C \frac{\partial T}{\partial t}\right]=-\left[\rho C u \frac{\partial T}{\partial x}\right]+\left[k \frac{\partial^{2} T}{\partial y^{2}}\right] \quad(f l u i d), \\
& \varepsilon\left[\rho \frac{\partial u}{\partial t}+\frac{T_{c}}{T_{\text {in }}}\left[\frac{\partial u}{T} \frac{\partial T}{\partial t}\right]\right]=-\frac{T_{C}}{T_{1 n}}\left[\frac{\rho u^{2}}{T} \frac{\partial T}{\partial x}\right]-\frac{1}{F r}\left[\rho F_{x}\right]-\left[\frac{\partial P}{\partial x}\right] \\
& +\frac{1}{\operatorname{Re}}\left(\frac{X_{c}}{Y_{c}}\right)^{2}\left[\mu \frac{\partial^{2} u}{\partial y^{2}}\right](\text { fluid). }
\end{aligned}
$$

This set of differential equations governs the coupled response of the core and the gas, using the approximations of low Mach number and thermally expandable flow. 
This system of coupled, time-dependent differential equations could be solved as it is written, including the fluid transient terms. However, if the scaling is proper and the characteristic quantities are indeed representative, each of the square-bracketed terms of the above system of equations is of unit order. Two simplifications that greatly reduce the computational effort in integrating the system arise if $\varepsilon$ is sufficiently small.

If the transient response of the solid core components is of major interest, the term $\varepsilon$ for the full-power FSV case is on the order of $10^{-2}$. The fluid temporal response is therefore negligible with respect to the fluid spatial response and both the temporal and spatial response of the solid core components. The fluid conservation equations can then be spatially integrated analytically. This leaves only the solid core components differential equation to be integrated in time.

However, if the transient time response of the fluid is of interest, the term $\varepsilon$ will appear on the right-hand side of the solid core component differential equation. Therefore, for the time period of interest of the characteristic fluid time, the temperature of the solid core components remains essentially constant. This can decouple the solid component equation from the system of equations. The transient response of the core components would still remain to be determined, but it would not need to be done simultaneously with the fluid equations.

For the computer codes developed in the HTGR Safety Analysis Program at Oak Ridge National Laboratory (ORNL), the core component response (i.e., fuel temperature) is of primary interest. In comparison with the energy storage term of the solid core components, the dynamic or time-dependent storage terms of the fluid conservation equations are neglected in $\mathrm{ORECA}^{8}$ and $\operatorname{CORTAP}^{9}$ to decrease computation costs without significantly affecting accuracy.

If the mass-storage term of the continuity equation [the first term on the left-hand side of Eq. (26)] is neglected, the straightforward expression that mass flux is constant in the fluid channel remains after spatial integration. This expression allows for fluid density changes, as would be expected when the fluid is either heated or cooled, as long as the fluid velocity is inversely affected. This velocity change can be observed in the momentum conservation equation as a spatial acceleration that is dependent upon fluid temperature gradient. It can be shown that the error committed by the constant fluid mass flux approximation if $\varepsilon$ is significantly less than unity is on the order of $\varepsilon$.

In general, this system of equations, Eqs. (45)-(48), can be described as stiff, where the fast-decaying components can adversely affect the allowable time step for numerical stability of an explicit method. It is possible, and desirable when the value of $\varepsilon$ can be affected by the advancing solution, to use a numerical method, usually implicit, specifically designed to yield numerically stable solutions at relatively large time-step values. This was done by Hedrick and Cleveland 10 for the water side of the BLAST steam generator simulation 
code where the widely varying water heat transfer coefficlent and node mass inventory could change a fast-decaying solution component to a slow-decaying component as the simulated transient develops.

If the value for $\varepsilon$ always remains negligibly small, it is computationally advantageous, as described by MacMillan, 11 to rewrite the system of differential equations to reduce the size and subsequent effort in computationally solving the problem.

Two situations, representing the extremes of operation at FSV, are investigated for their effect upon the value of $\varepsilon$. These involve analysis at ful1-flow and no-flow situations. The full-flow situation was described previously and will be examined further. The zero-flow situation will be analyzed in Chap. 4 .

The term $\varepsilon$ was derived as the ratio of the fluid characteristic time to the solid characteristic time. Slightly modifying the nomenclature for clarity, the characteristic quantities for the solid will be designated with a subscript of $s$ and the fluid characteristic quantities with an $f$, or $\varepsilon=t_{f} / t$. Substituting the derived characteristic times of the solid and fluid into this ratio yields

$$
\varepsilon=\frac{\left(\mathrm{X}_{\mathrm{c}} / \mathrm{U}_{\mathrm{c}}\right)_{f}}{\left(\rho_{\mathrm{c}} \mathrm{C}_{\mathrm{c}} \mathrm{T}_{\mathrm{c}} / \mathrm{Q}_{\mathrm{c}}\right)_{s}}=\frac{\mathrm{Q}_{\mathrm{s}}}{\rho_{\mathrm{s}} \mathrm{C}_{\mathrm{s}} \mathrm{T}_{\mathrm{s}}} \cdot \frac{\mathrm{X}_{\mathrm{f}}}{\mathrm{U}_{\mathrm{f}}} .
$$

Upon substituting the core conduction length $Y_{s}$ to eliminate the power density and then rearranging terms to satisfy the definitions of the known heat transfer and fluid flow dimensionless numbers, the term $\varepsilon$ can be written as

$$
\varepsilon=\frac{(\rho C)_{f}}{(\rho C)_{s}}\left(\frac{k_{s} / Y_{s}}{k_{f} / D}\right)\left(\frac{L}{Y_{s}}\right)\left(\frac{1}{\operatorname{Re} P r}\right) .
$$

This term is a product of the volumetric heat storage ratio and a grouping of geometric and thermophysical properties with fluid flow and heat transfer relationships. This term is similar to those developed by Sucec 12 and Perelman et a1.13 for conjugate heat transfer process of a solid and a fluid with different geometry from that of the HTGR.

The term $\mathrm{k}_{\mathrm{s}} / \mathrm{Y}_{\mathrm{s}}$ is a measure of the thermal conductance in the solid material. The term $k_{f} / D$ is a measure of the thermal conductance of the fluid in the channel. Both of these are unaffected by the flow circumstances. At a constant operating pressure where convection heat transfer dominates, the term $\varepsilon$ is therefore inversely proportional to the Reynolds number.

For full-power operation at FSV, the Reynolds number based on the channel diameter is $4.0 \times 10^{4}$. As $\varepsilon$ was shown to be on the order of 
$10^{-2}$, the Reynolds number at full-pressure conditions would have to decay to 400 for the fluid storage terms to be significant. This Reynolds number is well inside the laminar flow regime. However, as the Reynolds number decreases, thermal conduction heat transfer may dominate the heat transfer process, and use of a fluid velocity to scale the governing equations may be inappropriate. This situation will be investigated in Chap. 4.

Convection heat transfer to the fluid will arise at FSV even with a loss-of-forced-convection accident. Because of the natural circulation or thermosyphon effect induced by the temperature difference between low- and high-power regions, a significant gas velocity would be established in the core channels. A characteristic velocity for natural convection is $\sqrt{\mathrm{g} \Delta \mathrm{TL} / \mathrm{T}}$, where $\mathrm{g}$ is the gravitational acceleration, $\Delta T$ is the temperature difference between the hot and cold regions, $T$ is the average gas temperature, and $\mathrm{L}$ is the core height. This velocity is on the order of the forced convection velocity if the reactor remains at ful1system pressure, according to the analysis previously presented.14 The fluid transient storage terms remain negligible.

The volumetric heat capacity of the gas varies directly with the system operating pressure change. At depressurized conditions at FSV, the system pressure drops by a factor of 50 . If all other fluid flow factors remain constant, the fluid storage terms are even less significant than at full pressure. Because the helium circulators are constant volumetric flow devices, the Reynolds number will decrease directly as does the density, with no net effect upon the term $\varepsilon$. The fluid transient storage terms are still negligible.

Inherent is the assumption of thermally expandable flow as shown in Sect. 3.2. This assumption requires that the channel pressure drop be significantly less than the system operating pressure. This circumstance is true for all situations at FSV where the system operating pressure remains constant, either at full or atmospheric pressure. Otherwise, a fully compressible flow situation would necessitate a major change in the simplified governing equations and their numerical solution. 


\section{APPLICABILITY TO ZERO FLOW}

The characteristic scaling quantities used in Chap. 3 were specifically limited to the case where fluld convection is the dominant heat transfer mode for heat removal from the core. During a depressurization incident, another possible heat removal mechanism might also be apparent. This additional mechanism would be gas expansion cooling, where the gas consequently loses internal energy with the resulting temperature drop. The scaling in Sect. 3.1 resulted in neglecting the gas pressure-work term that must be included for this case. To show the limiting behavior of this process as the convection velocity approaches small values, the governing equations for the fluid will be rescaled with a zero characteristic velocity in all directions. This will show the effect of zero convection heat transfer on the fluid behavior.

The fluid conservation equations Eqs. (1)-(3) in the absence of an internal heat source are rewritten as

$$
\begin{aligned}
& \frac{\partial \stackrel{*}{p}}{\partial t}=0 \\
& 0=\stackrel{\star}{\rho} F_{1}-\frac{\partial *}{\partial \hat{P}_{1}},
\end{aligned}
$$

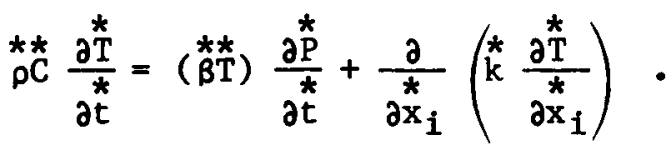

The continuity equation simply reduces to zero net density change with respect to time. The conservation of momentum simply reduces to hydrostatic relationship for the case where the acceleration of gravity induces the only body force. For this limiting condition, the timedependent terms for the continuity and momentum conservation relationships are identically zero.

The conservation of energy equation reduces to three terms dealing with transient temperature and pressure-work response and spatial conduction heat transfer. As helium can be considered an ideal gas for the FSV operating conditions, the term ( $\stackrel{\star * *}{\beta T})$ is identically one. By differentiating the ideal gas law with respect to time and using the equation of continuity, the energy conservation equation reduces to the following relationship: 


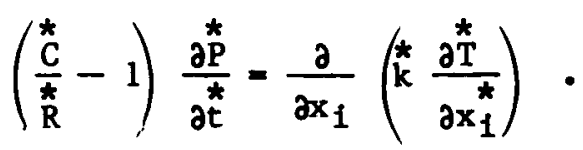

Upon substitution of characteristic and unit-order dimensionless quantities including thermodynamic identities and upon regrouping all the characteristic terms on the left-hand side, the energy conservation equation for a cylindrical channel reduces to

$$
\left(\frac{P_{f} D^{2}}{t_{f} k_{f} T_{f}}\right)\left[\frac{1}{r-1} \frac{\partial P}{\partial t}\right]=\left[\frac{1}{r} \frac{\partial}{\partial r}\left(r k \frac{\partial T}{\partial r}\right)\right],
$$

where the square-bracketed terms are of unit order. Also, axial thermal conductance in the fluid is still negligtble as shown previously for the convection case.

At the channel wall, the heat flux out of the solid component must balance the heat flux into the fluid. In dimensional terms this relationship is

$$
\stackrel{k}{\mathrm{k}}_{\mathrm{f}} \frac{\partial \stackrel{\mathrm{T}}{\mathrm{T}}_{\mathrm{f}}^{*}}{\partial \mathrm{r}_{\mathrm{f}}}=\stackrel{*}{\mathrm{k}}_{\mathrm{s}} \frac{\partial \stackrel{\mathrm{T}}{\mathrm{s}}^{*}}{\partial \mathrm{y}_{\mathrm{S}}}
$$

Upon substitution of the characteristic and unit-order dimensionless quantities, this heat balance can be rearranged in the following fashion.

$$
\left(\frac{k_{f} T_{f}}{D}\right)\left(\frac{Y_{s}}{k_{s} T_{s}}\right)\left[k \frac{\partial T}{\partial r}\right]_{f}=\left[k \frac{\partial T}{\partial y}\right]_{s} \text {. }
$$

The coefficient of the square-bracketed term on the left-hand side must be of unit order for the heat fluxes to balance. Substituting this relationship into Eq. (55) yields the following:

$$
\left(\frac{P_{f} Y_{s} D}{t_{f} k_{s} T_{S}}\right)\left[\frac{1}{r-1} \frac{\partial P}{\partial t}\right]=\left[\frac{1}{r} \frac{\partial}{\partial r}\left(r k \frac{\partial T}{\partial r}\right)\right] .
$$

All the characteristic quantities for the solid components have been determined previously, leaving the characteristic pressure $P_{f}$ as an 
independent variable to be determined. Because the most severe situation where the fluid equation is applicable would be a depressurization from full-system pressure to atmospheric, $P_{f}$ will be set to this pressure difference. For FSV, $P_{f}$ is then $4.75 \mathrm{MPa}$. The characteristic time $t_{f}$ for this particular depressurization situation would then be $0.7 \mathrm{~s}$. The characteristic time for the core remains at $40 \mathrm{~s}$ as shown in Sect. 3.3. The solid components characteristic time is on the order of 100 times that of the fluid for the depressurization case. The energy storage in the fluid is therefore much less than the energy storage in the core materials for this depressurization case.

Because the fluid continuity and momentum conservation equations are identically zero for this no-flow case, the dynamics of the scaled, coupled, energy conservation equations for the solid and fluid reduce to the following system:

$$
\begin{aligned}
& \left(\frac{P_{f} Y_{s} D}{t_{f} k_{s} T_{s}}\right)\left[\frac{1}{r-1} \frac{\partial P}{\partial t}\right]=\left[\frac{1}{r} \frac{\partial}{\partial r}\left(r k \frac{\partial T}{\partial r}\right)\right] \quad(\text { fluid), } \\
& \left(\frac{\rho_{s} C_{s} T_{s}}{Q_{c} t_{s}}\right)\left[\rho C \frac{\partial T}{\partial t}\right]=\left[k \frac{\partial^{2} T}{\partial y^{2}}\right]+[Q] \quad(\text { solid), }
\end{aligned}
$$

As before, the leading coefficient of the solid energy storage term is set to unity, and the term $\varepsilon=t_{f} / t_{s}$ is substituted into the coefficient of the fluid energy storage term. The following system emerges:

$$
\begin{aligned}
& \varepsilon\left[\frac{1}{r^{-1}} \frac{\partial P}{\partial t}\right]=\left[\frac{1}{r} \frac{\partial}{\partial r}\left(r k \frac{\partial T}{\partial r}\right)\right] \quad(f 1 u i d), \\
& {\left[\rho C \frac{\partial T}{\partial t}\right]=\left[k \frac{\partial^{2} T}{\partial y^{2}}\right]+[Q] \quad(\text { solid }),}
\end{aligned}
$$

where

$$
\varepsilon=\left(\frac{P_{f} Y_{s} D}{k_{s} T_{s}}\right)\left(\frac{Q_{c}}{\rho_{s} C_{s} T_{s}}\right) \text {. }
$$

This last relationship for $\varepsilon$, applicable for zero flow, can be reduced with the identities developed in Chap. 3 for the steady state case at full power to the following relationship: 


$$
\varepsilon=\left(\frac{\mathrm{P}_{\mathrm{f}}}{\rho_{\mathrm{s}} \mathrm{C}_{\mathrm{s}} \mathrm{T}_{\mathrm{s}}}\right) \quad\left(\frac{\mathrm{D}}{\mathrm{Y}_{\mathrm{s}}}\right)
$$

This characteristic time ratio has been calculated to be on the order of $10^{-2}$ for a depressurization from full-system pressure.

If the reactor remains at full pressure, with the channel flow going to zero, the characteristic pressure $P_{f}$ would be on the order of the hydrostatic head. This would be much less than the absolute pressure. The analysis for a depressurization with zero flow represents a bounding case for FSV. ratios:

The relationship for $\varepsilon$ can be observed as the product of two

$$
\frac{P_{f}}{\rho_{s} C_{s} T_{s}}=\frac{\text { pressure energy stored per unit volume of fluid }}{\text { thermal energy stored per unit volume of solid }},
$$

and

$$
\frac{D}{Y_{s}}=\frac{\text { thermal conduction length in fluid }}{\text { thermal conduction length in solid }} .
$$

For FSV, the ratio of $\mathrm{D} / \mathrm{Y}_{\mathrm{S}}$ is on the order of one, leaving the other ratio to be on the order of $10^{-2}$. If the thermal stored energy is on the order of the pressure stored energy, the neglect of the energy dynamic term of the fluid would not be valid. However, this situation would only arise if the reactor were operated at steady state conditions at a very low temperature when the depressurization occurred. Low temperature steady state operation prior to an incident is not of interest for HTGR safety studies simply because the fuel would not reach a high enough value for fission-product release. Indeed, for a depressurization from full-system pressure for FSV, the temperature drop of the core materials due only to the depressurization will be on the order of $2 \mathrm{~K}$ if energy storage in the fluid is to be considered. The fluid dynamic equations can be set to zero as was done in Chap. 3 with negligible error for all operating situations of interest. 


\section{CONCLUSIONS}

Analysis presented in Chaps. 3 and 4 for the HTGR safety analysis of FSV from high-power steady state operation shows that deletion of the dynamics of the fluid conservation equations is valid for both full-flow and zero-flow situations.

Deletion of the time-dependent terms of the conservation of mass, momentum, and energy equations for the fluid causes little error, because the characteristic response time of the solid components is two orders of magnitude greater than that of the fluid. Neglect of the fluid dynamic terms allows analyt1c spatial integration of the fluid conservation equations over the computational node length along the flow channel and results in an algebraic relationship. Only the dynamic response of the core materials requires computational integration in time. This simplification greatly decreases the computational cost of the HTGR safety analysis computer codes developed at ORNL. Additionally, density changes in the helium as a result of thermal addition were shown to be explicitly considered, even though the fluid mass storage dynamics are neglected. 
REFERENCES

1. L. A. Segel, "Simplification and Scaling," SIAM Review, 14, 547-71 (1972).

2. S.-I. Pai, Viscous Flow Theory, Vol. 1 - Laminar Flow, D. VanNostrand, Princeton, N. J., pp. 33-47, 1956.

3. G. K. Batchelor, An Introduction to Eluid Dynamics, Cambridge University Press, 1967.

4. F. M. White, Fluid Mechanic8, McGraw-H111, New York, p. 280, 1979.

5. J. Goodman et a1., The Thermodynamic and Transport Properties of Helium, GA-Al3400, GA Technologies, 1975.

6. C. A. Ha11, T. A. Porsching, and R. S. Douga11, Numerical Methods for Thermally Expandable Two-Phase Flow - Computational Techniques for Steam Generator Modeling, EPRI NP-1416, 1980.

7. Public Service Co. of Colorado, Fort St. Vrain Reactor, Final Safety Analysis Report, Docket 50-267.

8. S. J. Ball, ORECA-I: A Digital Computer Code for Simulating the Dynamics of HTGR Cores for Emergency Cooling Analyses, ORNL/TM5159, Union Carbide Corp. Nuclear Div., Oak Ridge Nat1. Lab., 1976.

9. J. C. Cleveland, CORTAP: A Coupled Neutron Kinetic-Heat Transfer Digital Computer Program for the Dynamic Simulation of the High Temperature Gas Cooled Reactor Core, ORNL/NUREG/TM-39, Union Carbide Corp. Nuclear Div., Oak Ridge Nat1. Lab., 1977.

10. R. A. Hedrick and J. C. Cleveland, BLAST: A Digital Computer Program for the Dynamic Simulation of the High Temperature Gas Cooled Reactor Reheater-Stean Generator Module, ORNL/NUREG/TM-38, Union Carbide Corp. Nuclear Div., Oak Ridge Natl. Lab., 1976.

11. D. B. MacMillan, "Asymptotic Methods for Systems of Differential Equations in Which Some Variables Have Very Short Response Times," SIAM J. Appl. Math., 16(4), 704-22 (1968).

12. J. Sucec, "Unsteady Heat Transfer Between a Fluid, with Time Varying Temperature, and a Plate: An Exact Solution." Int. J. Heat Mass Transfer, 18, 25-36 (1975).

13. T. L. Perelman et a1., "Unsteady State Conjugated Heat Transfer Between a Semi-Infinite Surface and Incoming Flow of a Compressible Fluid-I. Reduction to the Integral Relation," Int. J. Heat Mass Transfer, 15, 2551-61, (1972). 
14. J. C. Conk1in, "Therma1-Flow Performance of the Fort St. Vrain High-Temperature Gas-Cooled Reactor Core During Two Design-Basis Accidents," presented at the ANS/ASME Topical Meeting on Reactor Therma1-Hydraulics, Oct. 6-8, 1980, Saratoga, New York. 
ORNL/TM-10099

Dist. Category R8

\section{Internal Distribution}

23. A. P. Malinauskas

24. D. L. Moses

25. J. P. Sanders

26. R. S. Stone

27. M. L. Tobias

28. H. E. Tramme11

29. R. P. Wichner

30. J. H. Wilson

31. I\&C Publication of $f$ ice

32. ORNL Patent office

33. Central Research Library

34. Document Reference Section

35-36. Laboratory Records Department

37. Laboratory Records, RC

\section{External Distribution}

38. S. E. Fisher, Public Service Co. of Colorado, 2420 W. 26 th Ave., Suite 1000, Denver, CO 80211

39-42. Director, Office of Nuclear Regulatory Research, Nuclear Regulatory Commission, Washington, DC 20555

43. Chief, Advanced Safety Technology Branch, Division of Accident Evaluation, Office of Nuclear Regulatory Research, Nuclear Regulatory Commission, Washington, DC 20555

44. Office of Assistant Manager for Energy Research and Development, DOE, ORO, Oak Ridge, TN 37831

45-46. Technical Information Center, DOE, Oak Ridge, TN 37831

47-246. Given distribution as shown in category R8 (10-NTIS) 